\section{RESEARCH REVEALS DENTISTS ARE DOWN IN THE MOUTH}

Dentists are almost twice as likely as the general population to feel dissatisfied with life according to a recent survey on dentists' wellbeing. The research, carried out by the British Dental Association (BDA) last summer, found that dentists rated their levels of satisfaction with life and happiness, and whether the activities they engage in seem worthwhile at much lower levels than the wider population. They also reported higher levels of anxiety.

The survey, based on 481 responses from community dentists and 903 from GDPs, measured dentists' perceptions of their own well-being using four indicators developed by the Office of National Statistics. Among community dentists, almost half (47\%) of those surveyed reported low levels of life satisfaction and 55\% said they experienced high levels of anxiety during the day before they took part in the study. Similarly, almost half of GDPs surveyed (47\%) reported low levels of life satisfaction and around six out of ten said they experienced high levels of anxiety.

The Chair of the BDA's Principal Executive Committee, Mick Armstrong, said: 'It's hardly surprising that dentists are stressed - just providing good dental care for our patients and managing their increasing expectations within a shrinking budget is challenging. If that wasn't enough, dentists now practise under the shadow of litigation and arcane, over-zealous regulation.'

The BDA researchers observed that GDPs who do mainly NHS work reported lower levels of well-being than those doing mainly private work.

Armstrong warned that: 'Commissioners, managers and regulators would do well to heed these warning signs.'

The full report is available on the BDA website: https://www.bda.org/dentists/ policy-campaigns/research/ workforce-finance/gp/wellbeing.

\title{
THE REACTION...
}

\section{GDC ACCOUNTABILITY HEARING}

0 n Wednesday 11 March 2015 the General Dental Council's (GDC) Chair, Bill Moyes, and Chief Executive, Evlynne Gilvarry, appeared before the Health Select Committee (HSC) for the GDC's first ever accountability hearing. Moyes and Gilvarry came under unprecedented scrutiny. The Committee, chaired by Sarah Wollaston, pointed to written evidence from the Professional Standards Authority that described the regulator as worse than seven of the eight professional regulators it oversees. Here we summarise some of the reaction to the Committee hearing.

\section{Local Dental Committees (LDCs):}

Leaders of the LDCs called for the GDC Chair to step down following the 'thrashing from Health Select Committee'. This follows a vote in December 2014, when representatives of 90 out of the UK's 96 LDCs voted unanimously for a motion of no confidence in the GDC. Following the hearing, the leaders again called on Moyes and Gilvarry to "apply the standards they claim to uphold and restore confidence throughout dentistry by vacating their posts at the head of the GDC.'

\section{General Dental Council (GDC)}

According to the GDC itself: "the Chair and Chief Executive both welcomed the opportunity to attend the hearing. The GDC is wholly committed to achieving high standards of regulation and was pleased to engage with the HSC members regarding the range of measures that have been put in place to meet the challenges that face dental regulation.' The HSC shared the GDC's disappointment that legislative change had not occurred during the current Parliament.

\section{British Dental Association (BDA)}

Mick Armstrong, Chair of the British Dental Association's Principal Executive Committee, said: 'I want to thank Dr Wollaston and her colleagues for finally shining a light on the GDC. Important questions were posed, but answers were in short supply. They [The GDC] failed to show progress on concrete improvements, and conspicuously failed to take any responsibility for problems of their own making. Tellingly, we saw no evidence of the regulator's regret or willingness to engage positively with our profession. Let me extend my thanks to our members for making this possible. We are committed to seeing this through so, together, we can secure the regulation our profession deserves.'

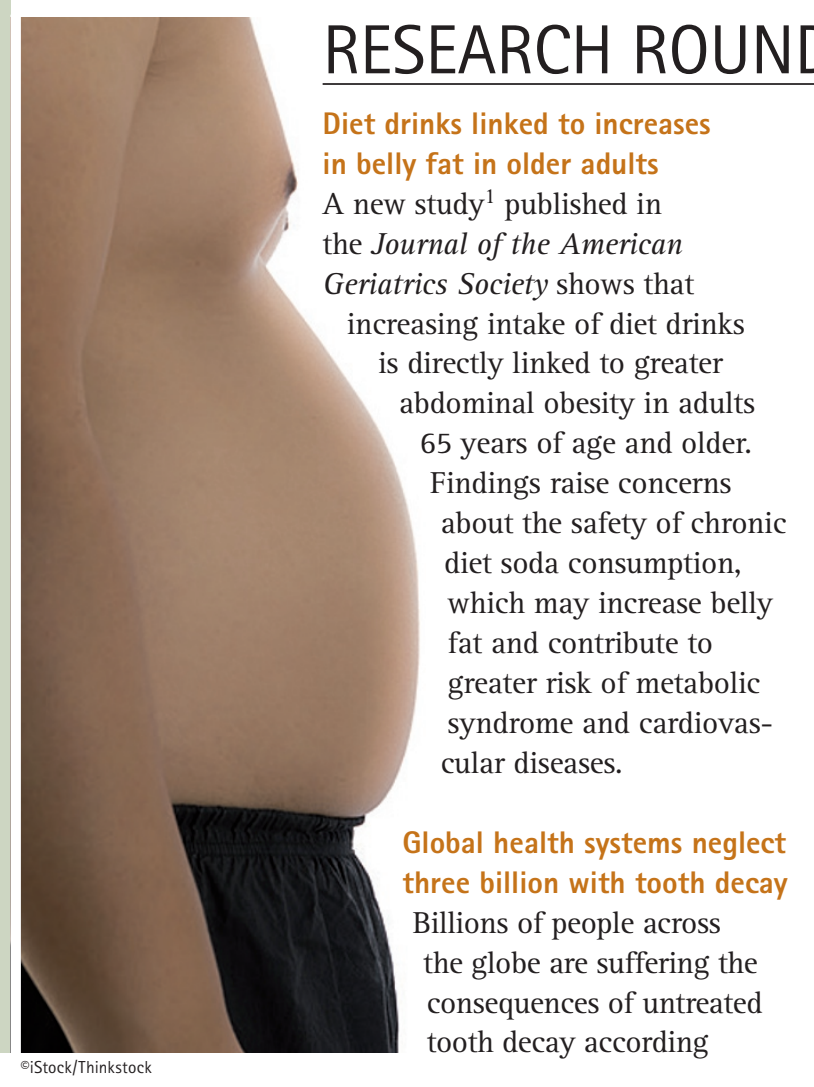

\section{RESEARCH ROUND-UP}

Diet drinks linked to increases in belly fat in older adults A new study ${ }^{1}$ published in the Journal of the American Geriatrics Society shows that ncreasing intake of diet drinks is directly linked to greate bdominal obesity in adults 65 years of age and older Findings raise concerns about the safety of chronic which may increase belly fat and contribute to greater risk of metabolic syndrome and cardiovascular diseases.

Global health systems neglect th tooth decay Billions of people across the globe are suffering the consequences of untreated tooth decay according to new research published in the Journal of Dental Research. Professor Wagner Marcenes of Queen Mary University of London led the Oral Health Research Group within the latest Global Burden of Disease study, which found 2.4 billion people worldwide have untreated tooth decay in their permanent teeth, and 621 million children have untreated tooth decay in their milk teeth. The researchers estimate over 190 million new cases of tooth decay in adults will develop annually worldwide.

1. Fowler S P, Williams K, Hazuda H P. Diet soda intake is associated with long-term increases in waist circumference in a biethnic cohort of older adults: the San Antonio longitudinal study of aging. J Am Geriatr Soc 2015; DOI: 10.1111/jgs.13376 [Epub ahead of print].

2. Kassebaum N J, Bernabé E, Dahiya M Bhandari B, Murray C J, Marcenes W. Global burden of untreated caries: a systematic review and metaregression. J Dent Res 2015; [Epub ahead of print]. 